\title{
Democracia e justiça social em tempos de golpe sob a égide do neoliberalismo
}

\author{
Maria Alexandra da Silva Monteiro \\ Mustafá ${ }^{1,2}$ \\ https://orcid.org/0000-0002-9011-6597
}

\section{Salyanna de Souza Silva ${ }^{3}$}

https://orcid.org/0000-0002-3329-4856

\author{
Gisele Caroline Ribeiro Anselmo ${ }^{4}$ \\ https://orcid.org/0000-0003-4130-1152
}

\begin{abstract}
${ }^{1}$ Universidade Federal de Pernambuco, Centro de Ciências Sociais Aplicadas, Departamento de Serviço Social, Recife, PE, Brasil (UFPE)

${ }^{2}$ Universidade Federal de Pernambuco, Centro de Ciências Sociais Aplicadas, Programa de Pós-Graduação em Serviço Social, Recife, PE, Brasil (UFPE)

${ }^{3}$ Universidade Estadual do Ceará, Centro de Estudos Sociais Aplicados, Mestrado Acadêmico em Serviço Social, Trabalho e Questão Social, Fortaleza, CE, Brasil (UECE)

${ }^{4}$ Pesquisadora autônoma, Rio de Janeiro, RJ, Brasil
\end{abstract}

\section{Democracia e justiça social em tempos de golpe sob a égide do neoliberalismo}

Resumo: O presente artigo objetiva dar centralidade à dimensão ética, frontalmente desvirtuada pelas tendências atuais da política nacional, comandada pelo ideário neoliberal, que contradiz toda forma e intencionalidade do princípio da justiça social. Metodologicamente recorreu-se a uma pesquisa documental, realizada em livros, em artigos da imprensa e em relatórios internacionais. O texto particulariza as razões que culminaram com o impeachment da presidenta Dilma e seus desdobramentos, no contexto do atual golpe de Estado, como expressão de negação da democracia e desmonte dos direitos sociais alcançados pelos trabalhadores nos últimos decênios.

Palavras-chave: Neoliberalismo. Democracia. Justiça Social. Política Social. Ética.

\section{Democracy and social justice in times of coup under the aegis of neoliberalism}

Abstract: This article aims to give centrality to the ethical dimension, which is fundamentally distorted by the current tendencies of Brazilian national politics, guided by the neoliberal ideology, which contradicts every form and intentionality of the principle of social justice. Documentary research was carried out using books, press articles and international reports. The article details the reasons that led to the impeachment of President Dilma and its developments in the context of the current coup d'état, as an expression of denial of democracy and dismantling of social rights achieved by workers in recent decades.

Keywords: Neoliberalism. Democracy. Social justice. Social Policy. Ethic.

Recebido em 18.06.2017. Aprovado em 08.02.2018. Revisado em 23.03.2018.

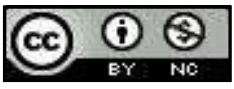

(C) O(s) Autor(es). 2018 Acesso Aberto Esta obra está licenciada sob os termos da Licença Creative Commons Atribuição-NãoComercial 4.0 Internacional (https://creativecommons.org/licenses/by-nc/4.0/deed.pt_BR), que permite copiar, distribuir e reproduzir em qualquer meio, bem como adaptar, transformar e criar a partir deste material, desde que para fins não comerciais e que você forneça o devido crédito aos autores e a fonte, insira um link para a Licença Creative Commons e indique se mudanças foram feitas. 


\section{Introdução}

O nível de igualdade ou de justiça social está diretamente relacionado às condições de adversidade, maiores ou menores, que se encontra uma sociedade, em cada momento histórico, para implementação do projeto socialista.

Para uma imersão no sentido mais profundo deste artigo, optou-se por seguir parâmetros éticos sobre a justiça social, que se constituem parte indispensável da reflexão e formulação ontológica e deontológica da profissão de assistente social, e que se contrapõem à versão propalada e difundida pelos mentores do neoliberalismo, tais como Friedrich Hayek e Milton Friedman.

A justiça social, princípio presente no atual Código de Ética Profissional (ABATH; MUSTAFÁ, 2006) e também na atual Constituição Brasileira (BRASIL, 2016), é associada à universalidade de acesso aos bens e serviços, materializados em programas e políticas sociais, que promovam a redistribuição da riqueza do País. Assim, a justiça social, enquanto associada à noção de ética, está intrinsecamente vinculada à efetivação e ampliação da democracia que, segundo Coutinho (2008), representa a socialização da política, do poder econômico, da riqueza, da cultura e do saber de um povo. Neste sentido, apesar do fato de existirem leis que a legitimam, a justiça se impõe, principalmente, pelo caráter ético e não só pela norma procedimental que a define. As normas são estabelecidas de acordo com a correlação de forças, e, numa sociedade de democracia representativa, como a nossa, as leis podem expressar posturas discriminatórias, autoritárias, preconceituosas e defender determinados interesses dos grupos hegemônicos no poder.

Com efeito, uma visão panorâmica sobre a conjuntura política e ideológica mundial indica a adoção hegemônica de tendências conservadoras, autodenominadas de neoliberalismo, que promovem um ataque frontal às políticas sociais e uma desconstrução do papel do Estado, enquanto órgão mediador e regulador da reprodução das classes trabalhadoras. Este ideário reafirma uma adesão sem limites aos interesses da burguesia nacional e internacional, restaurando fórmulas e reformas retrógadas e desumanizantes de escravismo nas relações de trabalho, e consolida uma concepção de trabalho que nega toda e qualquer possibilidade de o homem exercitar sua perspectiva teleológica, que é inerente à sua condição de sujeito e ser social.

Pretende-se, enfim, com este artigo, chamar a atenção para a tendência explícita do Estado em assegurar os interesses da burguesia e para a gravidade da ruptura com a democracia, que vem no sentido de reforçar uma tendência no País de ataques e contrarreformas, desde a sua promulgação, que ferem frontalmente a Constituição de 1988 e anula toda uma trajetória de conquista de direitos e lutas da população brasileira. Conclui-se, neste trabalho, que o tema da justiça social não cabe no universo conceitual e prático do neoliberalismo. Vale ressaltar que o neoliberalismo enquanto corrente de pensamento concentra uma gama plural e diferenciada de teóricos, em contextos nacionais e históricos diversos, podemos sinalizar também para diferentes variantes de sua implementação (CASTELO, 2013; KATZ, 2016), contudo tais características não alteram seu teor antidemocrático e conservador (SANTOS, 2007), constituinte da ordem desigual e imperialista capitalista.

\section{Conjuntura política mundial e neoliberalismo: a negação da justiça social}

O século XIX foi marcado pela constante disputa de projetos de sociedade e de concepções de mundo. Ao mesmo tempo em que o capitalismo chega a sua fase mais madura, ou seja, a fase dos monopólios, em tal período tivemos experiências de diversos movimentos e insurreições sociais, como a Comuna de Paris ${ }^{1}$, as Revoluções de 1848, a Revolução Russa de outubro de 1917, a Revolução de Cuba, dentre outros. As referidas experiências avançaram no sentido da construção de uma proposta socialista de justiça social no caminho para uma emancipação humana ${ }^{2}$. Por outro lado, no século XX tem-se em nível mundial o ataque e derrota dos países do socialismo real por meio de diversas medidas econômicas e políticas.

Nesse sentido, a partir do final dos anos 1960 e início dos anos 1970 do século passado, uma mudança em termos de orientação política e econômica para muitos países ocidentais. Tal mudança tem como base principal o retorno das taxas de lucro alcançadas durante os chamados trinta anos gloriosos. A causa do esgotamento do padrão de acumulação taylorista/fordista e buscando responder a um quadro de recessão generalizada, está articulada a um conjunto de respostas econômicas, sociais, políticas e culturais que transformam o desenvolvimento do capitalismo em nível mundial.

Da hipertrofia da esfera financeira à tendência de uma maior concentração de capitais, graças às fusões entre as empresas monopolistas/oligopolistas e ataque aos direitos trabalhistas e sociais, por meio de medidas de flexibilização/desregulamentação/privatizações, o capitalismo começa também um ataque aos postulados do chamado Welfare State ou Estado de Bem-Estar Social. Logo, são satanizadas as políticas keynesianas por basearem-se no estímulo à intervenção do Estado na economia. O marco teórico e filosófico que fundamenta tal nova reorganização do capital é o neoliberalismo. 
O embate entre Keynes e Hayek ${ }^{3}$ existia desde os anos da grande depressão (1929); se acirrou no pósSegunda Guerra (1945), com a formação da Associação Mont Pèlerin, mas o neoliberalismo só ganhou força, em nível mundial, entre os anos 1980 e 1990. Foi assim fortemente desenvolvido em diversos países, sobretudo nos Estados Unidos com Reagan e na Inglaterra com Thatcher. Em ambos os governos foram propostas reformas do Welfare State voltadas principalmente para o desmantelamento dos sistemas de proteção social, incluso a previdência e a saúde. Na Europa continental e nórdica, os programas neoliberais foram igualmente agressivos. A difusão do neoliberalismo se realizou principalmente por meio das instituições supranacionais, especificamente o Fundo Monetário Internacional (FMI), o Banco Mundial (BM) e a Organização para a Cooperação e Desenvolvimento Econômico (OCDE). Em nível europeu, por meio da Comissão Europeia, do Instituto Monetário Europeu e depois do Banco Central, que posteriormente inspirou dois projetos europeus: o mercado único e a União Econômica e monetária.

Para os países considerados em via de desenvolvimento, os princípios neoliberais foram as bases do pacote econômico ditado pelo Washington Consensus promovido pelo FMI e o Banco Mundial.

Vale ressaltar que depois da queda do muro de Berlim e da URSS (em 1989), ao capitalismo dos Estados Unidos interessava minar qualquer outra alternativa de projeto societário, ou seja, qualquer outra tentativa de reconstrução do socialismo.

Chossudovsky (1998) afirma que nos países da ex-União Soviética, como a ex-Iugoslávia, as medidas de contrarreforma de caráter neoliberal foram promovidas de forma incisiva, de modo a promover um verdadeiro genocídio econômico.

Associado ao incremento das tendências ideopolíticas de extrema direita, evidencia-se o crescimento de formas reacionárias, como a xenofobia, o racismo e o revigoramento do nazismo e do fascismo, em todo o mundo, no contexto da crise mundial, na qual, o neoliberalismo contribui decisivamente para o descompasso da distância entre ricos e pobres, inserida aí o combate aos migrantes e ex-colonos dos países especialmente europeus e norte-americanos.

Neste sentido, é importante observar como o neoliberalismo se desenvolveu na América Latina: aqui ele associou-se à repressão ditatorial e à violência. Afirma o filósofo argentino Tognonato (2014), que antes de difundir-se aos demais países do mundo, o neoliberalismo passou por uma fase de experimentação com o ditador Pinochet no Chile em 1973.

Naquele momento, na América Latina - o continente que sempre foi vigiado pelos Estados Unidos existiam grupos que procuravam construir um projeto contrário àquele hegemônico norte-americano. Tomemos como exemplo o vizinho cubano e o êxito da Revolução de Fidel Castro, que em 1 de janeiro de 1959 destituiu o ditador Fulgêncio Batista, e, sob a influência da então União Soviética, o governo Castro iniciou diversos programas socioassistenciais e econômicos. É sob esse espírito socialista que em 4 de novembro de 1970, no Chile, vence Salvador Allende que institui o governo Unidad Popular. A partir do exemplo de Cuba, iniciou reformas para o bem-estar social e econômico da população, como a nacionalização de alguns setores estratégicos para a economia do país e políticas sociais redistributivas. Era assim "um governo em nome da sociedade que se opõe aos monopólios estrangeiros e às lógicas do mercado". (TOGNONATO, 2014, p. 165, tradução nossa).

Se entre os(as) chilenos(as) Allende era consagrado, aos olhos dos Estados Unidos era considerado como falimento da sua influência e, por isso, um governo para ser derrubado. E de fato, o foi por meio do golpe de Estado de 11 de setembro de 1973, com o general Augusto Pinochet. Durante a ditadura que se segue veem-se fechado o parlamento, proibidas as manifestações de qualquer tipo e atividades partidárias e sindicais, além da violência e milhares de prisões, mortes e torturas (TOGNONATO, 2014). É nesse ambiente de não democracia que se inicia o programa neoliberal idealizado por Milton Friedman. Com cortes fiscais, privatizações de serviços, empresas e bancos, livre comércio, notáveis reduções na despesa social pública, em benefício dos grandes investimentos financeiros.

Vale observar que, nesse período, em praticamente todos os países da América Latina se evidenciava o regime da ditadura militar. No final dos anos 1980, à América Latina vem-se pro(im)posto o modelo econômico neoliberal que se traduziu em: privatização das empresas estatais; desregulamentação das economias nacionais; liberalização do mercado; redução do papel econômico do Estado e diminuição da despesa pública; reforma tributária para conter o déficit público; eliminação de cada tipo de restrição e taxas alfandegárias sobre os produtos de importação; liberalização dos investimentos provenientes do exterior; e reforço do setor privado com eliminação dos subsídios (CHOSSUDOVSKY, 1998).

Sendo assim, as políticas neoliberais foram mais radicais e destrutivas nos países da ex-União Soviética e da América Latina. As consequências para tais países foram diversas: a ruína econômica e política; o crescimento das taxas de desemprego; as pequenas e médias empresas nacionais faliram porque não conseguiram competir com as multinacionais; salários baixos, aumento das desigualdades em nível nacional e regional. As despesas sociais foram cortadas, as empresas estatais privatizadas ou fechadas e, concomitantemente 
ao desmantelamento do welfare state, cresceram as iniciativas privadas e de assistência, justamente como propuseram Hayek e Friedman (TOGNONATO, 2014).

O relatório da organização internacional OXFAM (2017), afirma que a concentração de riqueza no mundo é tal que apenas 8 bilionários detém uma renda total equivalente à metade da população mais pobre do mundo. É nesse contexto que vemos o fortalecimento do neoliberalismo, defendido como uma alternativa para a crise econômica. Ao analisar seja o discurso de seus pensadores e idealizadores, seja os elementos históricos do seu desenvolvimento na atualidade, é possível concluir que o neoliberalismo expressa um projeto político que objetiva a reprodução do capitalismo por meio de medidas antidemocráticas, autoritárias e ditatoriais.

\section{Justiça Social versus neoliberalismo: uma questão teórica e ética}

Foi sinalizado, acima, que a noção de justiça social, defendida pelo Código de Ética Profissional do Serviço Social, vai além da mera justiça normativa: fundamenta-se no reconhecimento de situações históricas de desigualdade e exploração, na implementação e fortalecimento de políticas sociais universais que rompam com o caráter fragmentário e seletivo.

Todavia, o que preconizam os autores neoliberais sobre a ideia de justiça? Qual sua concepção de sociedade e indivíduo?

Os principais expoentes teóricos da corrente neoliberalista são a Escola Austríaca, com Ludwig von Mises (1881-1973) e seu pupilo Friedrich Hayek (1899-1992) e a Escola de Chicago, com Milton Friedman (1912-2006). Este último assume uma particular importância para a análise do desenvolvimento e implementação do neoliberalismo na América Latina.

Enquanto corrente de pensamento filosófico, o neoliberalismo coloca em primeiro lugar o princípio da liberdade, incompatível com aquele da justiça social. Trata-se da "liberdade econômica, fortemente relacionada ao sucesso econômico, pois permite a busca do sucesso de acordo com percursos descentralizados, e que atingem diretamente o coração da questão do livre mercado". (RITZER, 2012, p. 404, tradução nossa) ${ }^{4}$.

Já a justiça social é entendida por Hayek como justiça distributiva e como limite ao mercado e, em última instância como expressão de abuso de poder do Estado, na medida em que induz este último à imposição de regras para a distribuição dos bens, tal como o fizeram os países do Leste europeu e a União Soviética, que sacrificaram as liberdades individuais em detrimento da justiça social.

Para os liberais, as coerções sofridas pelos indivíduos representam um mal que lhes impede de utilizar toda a sua capacidade e potencialidade mental, pois sob o estado de coerção, as ações individuais dependem inevitavelmente da vontade de um outro. É essa dependência que, segundo Hayek, seria negativa para o desenvolvimento individual.

São, portanto, os indivíduos singulares que, no exercício da sua liberdade, realizam grandes progressos humanos. Logo, o liberalismo reforça o indivíduo isolado na sua vida presente. Se a sociedade é a soma dos indivíduos que, no relacionar-se uns com os outros se auto ameaçam, cabe a tais sujeitos desenvolverem posturas egoístas, a fim de garantirem a sua existência. Mesmo em situações de cooperação, os indivíduos devem colocar suas necessidades pessoais acima do coletivo. Afirma Friedman (2016, p. 168) que "as pessoas cooperam umas com as outras porque assim são capazes de satisfazer os próprios desejos com mais eficácia".

Hayek explica que a liberdade individual se expressa na existência de um estado de liberdade, no qual o indivíduo pode agir sem ser obrigado e constrangido pelos outros, nem por uma instância superior. Todavia, pelo fato de viver em sociedade, torna-se difícil para a pessoa não sofrer coerções, daí a necessidade da instituição do Estado, que deve ter um papel limitado ao mínimo, isto é, proteger as esferas privadas e criar "as condições que consentem ao indivíduo decidir o próprio comportamento, através de normas que digam o que o Estado fará nas variadas situações”. (FRIEDMAN, 2016, p. 49).

Essa corrente filosófica baseia-se na ideia de que somente nas condições de livre mercado é possível alcançar a liberdade democrática e os direitos civis, opondo-se abertamente à planificação da economia, presente nos países da União das Repúblicas Socialistas Soviéticas (URSS), como também na proposta keynesiana.

Ao centro se encontra o estado de liberdade individual que, a partir do momento em que o indivíduo procura construir-se singularmente, persegue, concomitantemente, o interesse da própria sociedade, bem na perspectiva de mão invisivel de Adam Smith.

Para além do acúmulo de bens, tal perspectiva considera que a maior conquista do capitalismo foi aquela de dar aos indivíduos a oportunidade de ampliar, desenvolver e melhorar as próprias capacidades, o que se contrapõe frontalmente ao pensamento de Marx, quando afirma que o projeto societário comunista é emancipatório, porque sem as amarras do trabalho assalariado e da divisão social do trabalho, os indivíduos poderão desenvolver ao máximo suas potencialidades e exercer plenamente a sua liberdade. 
Resta saber que, se o capitalismo representa a melhor forma de gestão da sociedade, como os liberais e neoliberais explicam os fenômenos da desigualdade econômica e social? Segundo Friedman (2016, p. 164), o princípio ético que justificaria a redistribuição da riqueza na "sociedade de mercado livre" se expressa na máxima "a cada um de acordo com o que produz, por suas qualificações e por seus instrumentos".

Entende-se que cada indivíduo é livre para escolher o próprio trabalho e através da sua realização, recebe o pagamento de acordo com o produto concretizado; porém, além da diferença na ocupação profissional, existem diferenças entre as pessoas, daí porque o mercado paga de maneira desigual, justamente para compensar tal diversidade.

Esta é mais uma das questões tratadas por Marx na Crítica ao Programa de Gotha. Ao equiparar a proposta de Lassale aos princípios basilares da sociedade burguesa, Marx afirma que, para que haja uma justa divisão da riqueza, não basta ao indivíduo receber o correspondente ao que produz, mas cabe esperar "de cada um de acordo com suas potencialidades e para cada um, de acordo com suas necessidades". (MARX, 1990, p. 110). Ao acrescentar o fator necessidades, Marx apresenta a mais fiel concepção ética de justiça social e supera qualquer argumento falacioso de justificativa da desigualdade na distribuição da riqueza na sociedade de livre mercado.

Com efeito, esta desigualdade vem entendida pelos neoliberais, como uma derivante das imperfeições do mercado e também como consequência das intervenções públicas anteriores, como por exemplo das políticas keynesianas.

Recorrendo a exemplos hipotéticos e descontextualizados, que incluem na tese de aquisição de riqueza o fator sorte, Friedman justifica a visão egoísta e ahistórica de mundo, na qual não cabe considerar se a sociedade foi fundada na escravidão ou na exploração da mão de obra, nem conceber a organização daqueles que tiveram azar, pois "a grande realização do capitalismo não tem sido a acmulação de propriedades, mas sim, as oportunidades que oferece a homens e mulheres para aplicar, desenvolver e aprimorar suas capacidades". (FRIEDMAN, 2016, p. 171). Isto, em outras palavras, redimensiona o poder coercitivo do Estado para com as manifestações e lutas da classe trabalhadora por direitos sociais. Mais uma vez, o Estado se faz necessário e sinaliza o fato de que não se pode cometer o erro de acostar as teorias liberais àquelas anarquistas.

Nesse sentido, o próprio pai do liberalismo (Adam Smith) era consciente da necessidade de intervenção do Estado. Para Smith, o laissez-faire, baseado na liberdade do mercado, precisa de um certo equilíbrio, ou um ambiente harmônico, que somente a intervenção de algumas instituições poderiam proporcionar. O Estado, para ele, possui um papel importante para a continuidade do sistema econômico. Mesmo se reduzidas, suas atividades são imprescindíveis. Os deveres do Estado são concernentes à segurança da ordem jurídica e à defesa dos direitos civis e políticos. Em outras palavras, é desaconselhado ao Estado participar das atividades econômicas, contudo sua presença é necessária nos âmbitos pouco atraentes para o mercado, como nas obras públicas e na instrução dos cidadãos.

Sendo consciente que a experiência do welfare state deixou na sociedade um importante modelo de atuação contra a questão social ${ }^{5}$, Hayek (1996) por sua vez, procura refletir sobre as funções do governo em relação aos serviços. Ele afirma que a dificuldade na oferta dos serviços sociais é própria aquela de abandono dos princípios liberais.

Assim, se os liberais do século XIX começam a admitir a necessidade de discutir sobre a redistribuição da riqueza e alguns serviços, tal mudança é em parte atribuída às influências de um "sentimento humanitário e igualitário" e de uma "mentalidade coletivista" de inspiração socialista e comunista (HAYEK, 1996, p. 49, tradução nossa). Concebem, portanto, que as intervenções do Estado devem ser de caráter meramente paternalista que, como afirma Friedman (2016), deve ser focalizado para aqueles que, segundo ele, podem ser considerados indivíduos irresponsáveis, como, por exemplo, as pessoas com transtorno mental e as crianças. Sendo assim, as experiências do Estado paternalista direcionadas para outros segmentos da sociedade não 
podem ser justificadas. Nesse sentido, as experiências dos programas habitacionais populares, as legislações sobre o salário mínimo e o subsídio aos preços dos produtos agrícolas demonstram que antes de melhorarem as condições de vida das pessoas, levam a um efeito oposto e, ao invés de contribuir para a redução do número de pessoas pobres, o elevam. Da mesma forma, são combatidas todas as políticas sociais.

Tanto Friedman, quanto Hayek propõem que se repasse a administração dos serviços previdenciários e assistenciais aos pobres às empresas e à beneficência privada, pois estas, a partir dos impostos locais, podem oferecer serviços de proteção essenciais à população.

Nesses parâmetros, Friedman (2016) considera que as intervenções para reduzir a pobreza são sim importantes, não somente para os beneficiários, mas também para os contribuintes que as pagam por meio de suas taxas, ou seja, para aqueles que, sempre segundo suas palavras, podem se sentir angustiados com a pobreza.

Como se pode observar, para tais autores, a desigualdade é um fato natural e fruto do mérito individual. Não se leva em consideração a exploração nas relações de trabalho, nem se evidenciam as vidas dos sujeitos subalternos, as suas histórias. Estes são considerados incapazes de aproveitar as condições oferecidas pela sociedade liberal.

Embora Friedman venha afirmar que o capitalismo, sob os preceitos neoliberais, é um sistema baseado na democracia e liberdade individual, concretamente, seja no passado, que atualmente, a história vem revelando que, em realidade, para se desenvolver plenamente, o neoliberalismo faz uso de medidas antidemocráticas e neoconservadoras como ditaduras.

Assim, em acordo com David Harvey, constata-se que o aparato conceitual no qual se fundamenta o neoliberalismo, ou seja, a dignidade humana e a liberdade individual, não passam de conceitos abstratos e alienados, instrumentalizados somente para contribuir no processo da hegemonia do capital: "quando os princípios neoliberais conflitam com a necessidade de restaurar ou sustentar o poder da elite, esses princípios são ou abandonados ou tão distorcidos que se tornam irreconhecíveis". (HARVEY, 2013, p. 28).

\section{A justiça social ultrajada no Brasil em tempos de golpe}

De um contexto de várias críticas e com o surgimento de novas organizações contrárias aos postulados do capitalismo mundial, a partir dos anos 2000, na América Latina, inicia-se um importante processo de transformações políticas, que pode ser representado principalmente pela vitória democrática e eleitoral à presidência da república de partidos historicamente considerados de esquerda.

Em 2003, no Brasil, com o Partido dos Trabalhadores (PT) inicialmente com Luiz Inácio Lula da Silva (por dois mandatos) e depois com Dilma Rousseff, a partir de 2011. Em 2006, na Bolívia, com o Partido Movimentos para o Socialismo, com Evo Morales. No Chile, em 2006, com Michelle Bachelet. No Equador, com Rafael Correa, em 2007, no Paraguai com Fernando Lugo em 2008, no Uruguai com o partido Frente Amplio com Tabaré Vázquez, em 2005, e José Mujica, em 2010, e novamente Vázquez em 2015. Na Venezuela, em 2002 com Hugo Chávez Frias de 2002 a 2012 e depois com Nicolás Maduro Moros em 2013.

Muitos desses países realizaram oposições às políticas do FMI, alguns com posturas mais radicais como a Venezuela. Contudo, foi emblemática a escolha coletiva pela reprovação e não aceitação da extensão do Tratado Norte-Americano de Livre Comércio (NAFTA) e criação de uma área de comércio e mercado único no continente.

Esses governos não somente voltaram suas atenções para a economia ${ }^{6}$, mas também para a questão social, com a implementação de políticas e serviços sociais focalizados principalmente no desenvolvimento de programas nacionais de transferência de renda aos grupos historicamente considerados pobres.

No âmbito da doutrina neoliberal, observa-se que seu desenvolvimento e implicações dependem das formações econômico-sociais, bem como da relação destas com o capitalismo mundial. Assim, a partir de um "desenvolvimento geográfico desigual" (HARVEY, 2013, p. 23), a doutrina neoliberal, ao encontrar resistência na sua aplicação pura, tende a adotar variantes. Castelo (2013) afirma que a primeira variante ideológica foi intitulada receituário-ideal e que, particularmente nos anos 1990, inicia-se a variante social-liberal, caracterizada por ser uma derivação que mescla o modo de ser e agir do liberalismo com vagas intenções progressistas.

No caso do Brasil, ao analisar os governos de Lula da Silva e Dilma Rousseff, Alves (2016) afirma que tais governos de caráter neodesenvolvimentista ${ }^{7}$ apresentam também uma contradição visceral da arquitetura geopolítica, pois se de um lado implementaram uma política externa contra-hegemônica ao império neoliberal, de outro lado não romperam com o Estado neoliberal implementado nos governos anteriores.

Todavia, não podemos ignorar os avanços no campo social. Foram regulamentados direitos sociais, já promulgados pela Constituição de 1988 (BRASIL, 2016), implantadas políticas sociais, tais como as políticas da pessoa idosa, por meio do Estatuto do Idoso (BRASIL, 2003), política de combate à violência contra a mulher, através da Lei Maria da Penha (BRASIL, 2006), de enfrentamento ao racismo, através do Estatuto da Igualdade 
Racial (BRASIL, 2010). Em especial, a política de assistência social foi colocada ao centro do agir do Estado, por meio principalmente dos Programa Fome Zero (2003-2011) e Brasil sem Miséria (2011-2016). Destaca-se também a Lei ${ }^{\circ}$ 12.435/2011 (BRASIL, 2011), que transformou a assistência social em uma política de Estado.

Contudo, contraditoriamente, em tais governos foram realizadas diversas contrarreformas, Salvador (2012) afirma que se por um lado os programas de transferência de renda e uma política de valorização do salário mínimo contribuiram para a redução da desigualdade de renda no Brasil, por outro lado "a queda da desigualdade da renda vem limitado a mudança na distribuição de rendimentos dentro da classe trabalhadora sem alteração da distribuição funcional da renda entre trabalho e capital”. (SALVADOR, 2012, p. 8).

Das análises acima expostas sobre a (i)lógica neoliberal, podemos extrair a conclusão de que as administrações alicerçadas nas políticas sociais desaguam num confronto ideológico-econômico, no qual as críticas capitalistas, especialmente em momentos de crise do capital, desconsideram por completo qualquer emanação ética, seja no que se refere aos direitos humanos, seja no que se refere à justiça social, tendo como hipótese que é preferível sacrificar os trabalhadores do que danificar a economia.

Vale destacar também o terreno histórico da burguesia brasileira, que como bem analisa Florestan Fernandes (2006), não foi capaz de realizar uma revolução de caráter nacional-democrático, ao aliar-se com setores oligárquicos nacionais e com o capital internacional, consubstanciando uma formação de Estado autocrático e ultraconservador.

$\mathrm{O}$ alvo por excelência da crítica da direita neoliberal é o Partido dos Trabalhadores, recorrendo a argumentos técnicos a partir dos quais constrói acusações, de ordem moral, política e ideológica, distorcendo o fato de que a crise econômica é mundial e não consequência das políticas e programas sociais, voltados para o atendimento de necessidades elementares dos segmentos pauperizados.

Neste contexto, emergem os conservadores como protagonistas de uma campanha difamatória intensiva contra o PT, especialmente nas figuras do ex-presidente Lula e contra a então presidenta Dilma Rousseff, transformando a ideologia neoliberal em senso comum, através do controle da mídia escrita e televisiva, atraindo para si o apoio massivo da classe média-alta e de setores mais vulneráveis, cultural e economicamente, da população, servindo-se de argumentos similares àqueles utilizados nos Estados Unidos da Améri$\mathrm{ca}$, à época do macarthismo ${ }^{8}$.

A política brasileira atual se caracteriza pela ruptura com a democracia, através de um golpe de Estado institucional que, recorrendo ao instrumento do impeachment, aparelhado e orquestrado por um movimento de direita e sob a falsa alegação de uso da justiça normativa, destituiu do poder central a presidenta Dilma Rousseff, impedindo-a de continuar a sua gestão legitimamente democrática. Assume o cargo de presidente Michel Temer, que, de imediato, instituiu como ministros um grupo de políticos e técnicos de direita e neoliberais.

A então presidenta Dilma foi acusada de crimes administrativos (popularmente conhecidos como pedaladas fiscais e de improbidade administrativa) por ter, em momentos de emergência, feito movimentações internas no governo para não retardar benefícios de programas sociais, e foi conduzida ao impeachment.

Apesar do sucesso das investidas da direita neoliberal, suas ações foram julgadas por juristas nacionais e internacionais, em um fórum da $\mathrm{ONU}$, que não viram razões justas, sequer do ponto de vista constitucional, para o impeachment da presidenta. A esse respeito, a revista Forum se manifestou da seguinte maneira:

\begin{abstract}
O processo de impeachment contra Dilma Rousseff 'viola a Constituição brasileira, a Convenção Americana de Direitos Humanos e o Pacto Internacional de Direitos Civis e Políticos, constituindo um verdadeiro golpe de Estado', segundo decisão proferida nesta quarta-feira (20/07) pelo Tribunal Internacional pela Democracia no Brasil, que reuniu juristas de vários países para julgar a legalidade das ações que levaram ao afastamento da presidente brasileira. (BENVENUTI, 2016).
\end{abstract}

Não existe dúvida, portanto, que se tratou de um golpe de Estado, um golpe na democracia, ainda tão recente no Brasil. Entendemos assim que o golpe de 2016 reitera o drama crônico brasileiro, entendido por Florestan Fernandes como um círculo vicioso que se repete reatualizando e reafirmando traços da hetoronomia e do conservadorismo da burguesia nacional que se materializam no Estado e na sociedade civil. Dessa forma, conforme analise de Fernandes (2006), a burguesia nacional não foi capaz de realizar a revolução burguesa, nos moldes da burguesia dos países europeus.

Dessa forma, no Brasil a burguesia nacional se aliou aos setores mais reacionários, como a aristocracia escravagista, o que desencadeou uma classe dominante e política antinacional, antidemocrática e antipopular, submissa também ao capital internacional, em especial à burguesia norte-americana, capaz de adotar mecanismos e instrumentos antidemocráticos frente a qualquer expressão de organização dos grupos subalternos.

Vale ressaltar que as primeiras medidas do governo golpista foram no sentido de desconstruir as políticas sociais existentes e atacar frontalmente os direitos sociais e trabalhistas, através principalmente de medidas pelo 
alto, como por exemplo diversas Propostas de Emendas Constitucionais, como a PEC 241, que veio a ser aprovada, por meio de lobbies e de um jogo de influências, na câmara dos deputados, atualmente Emenda Constitucional 95.

Ao colocar um limite para os gastos da União pelas próximas duas décadas, a PEC 241 institucionaliza um ajuste fiscal permanente e ignora uma eventual melhora da situação econômica do País. De acordo com a proposta, a regra que estabelece o teto de gastos a partir da correção da inflação não poderá ser alterada antes do décimo ano de vigência. O prazo final dessa política de austeridade se completaria em 20 anos. Dessa forma, o Novo Regime Fiscal proposto pelo governo Temer retira da sociedade e do Parlamento a prerrogativa de moldar o orçamento destinado às áreas de educação e saúde, que só poderá crescer conforme a variação da inflação. (ENTENDA..., 2016).

O presente governo ilegítimo e golpista visa realizar um complexo de contrarreformas no sentido de colaborar com a exploração e apropriação da mais-valia produzida pela classe trabalhadora (daí a aprovação da contrarreforma trabalhista e da flexibilização dos direitos das(os) trabalhadores), bem como se apropriar também do fundo público da Seguridade Social, beneficiando o capital internacional financeiro.

Da análise de tudo o que foi exposto neste item, pode-se facilmente concluir que o projeto neoliberal está sendo implementado com toda a sua força na sociedade brasileira e que as condições de vida e de trabalho da população estão cada vez mais afetadas para assegurar a acumulação da riqueza e a sobreposição do capital sobre o trabalho, o que, em outras palavras, atinge frontalmente os princípios da ética e da justiça social.

\section{Considerações finais}

Para além de uma análise meramente política, tentou-se aqui estabelecer os vínculos entre o fortalecimento do neoliberalismo e sua desarticulação com a ética e a justiça social. Tomou-se como exemplo particular a história recente da política brasileira, na qual se sobressaem aspectos de ordem filosófica, econômica, social e ética, seguindo um lastro de influência intelectual e midiática, com reflexos sociológicos negativos para a vida dos brasileiros. O que está em jogo é o fato de que, se a coalisão de uma burguesia financeira, militar, e até mesmo religiosa, volta a formar um cartel internacional para controlar os poderes judiciários e legislativos das nações e para restaurar a escravidão laborativa de antes, mascarada de pseudolegal, trata-se não apenas de um golpe aos direitos humanos, econômicos e sociais, mas chega a violar a concepção ético-politica dos projetos societários emancipatórios e da justiça social. Desta forma, o que está sendo questionado aqui é o real significado da democracia, que só pode se realizar de fato na medida em que se instale a justiça social. Com efeito, a concepção minimalista e procedimental de democracia pressupõe o direito ao voto, mas a concepção subversiva exige também a socialização da política e dos mecanismos de poder e a socialização dos meios de produção e da riqueza produzida socialmente.

\section{Referências}

ABATH, E. M; MUSTAFÁ, M. A. M. Códigos de Ética Profissional do/da Assistente Social, Grupo de Estudos e Pesquisas sobre Ética (GEPE). Recife: UFPE, 2006.

ALVES, G. O golpe de 2016 no contexto da crise do capitalismo neoliberal. Blog da Boitempo, São Paulo, 08 jun. 2016. Disponível em: $<$ https://blogdaboitempo.com.br/2016/06/08/o-golpe-de-2016-no-contexto-da-crise-do-capitalismo-neoliberal/>. Acesso em: 27 out. 2016.

BENVENUTI, P. Impeachment de Dilma é golpe de Estado, determina Tribunal Internacional pela Democracia. Forum, Santos, SP, 21 jul. 2016. Disponivel em: <http://www.revistaforum.com.br/2016/07/21/impeachment-de-dilma-e-golpe-de-estado-determina-tribunalinternacional-pela-democracia/>. Acesso em: 24 jan. 2017.

BRASIL. Lei n ${ }^{\circ} 10.741$, de 01 de outubro de 2003. Dispõe sobre o Estatuto do Idoso e dá outras providências. Diário Oficial da União, Brasília, DF, 03 out. 2003. Disponível em: <http://www.planalto.gov.br/ccivil_03/leis/2003/110.741.htm>. Acesso em: 24 jan. 2017.

. Lei $\mathrm{n}^{\circ} 11.340$, de 07 de agosto de 2006. Cria mecanismos para coibir a violência doméstica e familiar contra a mulher, nos termos do $\S 8$ o do art. 226 da Constituição Federal, da Convenção sobre a Eliminação de Todas as Formas de Discriminação contra as Mulheres e da Convenção Interamericana para Prevenir, Punir e Erradicar a Violência contra a Mulher; dispõe sobre a criação dos Juizados de Violência Doméstica e Familiar contra a Mulher; altera o Código de Processo Penal, o Código Penal e a Lei de Execução Penal; e dá outras providências. Diário Oficial da União, Brasília, DF, 08 ago. 2006. Disponível em: <http://www.planalto.gov.br/ccivil_03/_ato20042006/2006/lei/111340.htm>. Acesso em: 24 jan. 2017.

. Lei $\mathrm{n}^{\circ}$ 12.288, de 20 de julho de 2010. Institui o Estatuto da Igualdade Racial; altera as Leis no $\mathbf{\text { os }} 7.716$, de 5 de janeiro de 1989, 
9.029, de 13 de abril de 1995, 7.347, de 24 de julho de 1985, e 10.778, de 24 de novembro de 2003. Diário Oficial da União, Brasília, DF, 21 jul. 2010. Disponível em: <http://www.planalto.gov.br/ccivil_03/_ato2007-2010/2010/lei/112288.htm>. Acesso em: 24 jan. 2017.

. Lei $\mathrm{n}^{\circ} 12.435$, de 06 de julho de 2011. Altera a Lei no 8.742 , de 7 de dezembro de 1993, que dispõe sobre a organização da Assistência Social. Diário Oficial da União, Brasília, DF, 07 jul. 2011. Disponível em: <http://www.planalto.gov.br/ccivil_03/_ato20112014/2011/lei/112435.htm>. Acesso em: 24 ja. 2017.

Constituição da República Federativa do Brasil: texto constitucional promulgado em 5 de outubro de 1988, com as alterações determinadas pelas Emendas Constitucionais de Revisão n ${ }^{\text {os }} 1$ a 6/94, pelas Emendas Constitucionais nos $1 / 92$ a $91 / 2016$ e pelo Decreto Legislativo $n^{\circ}$ 186/2008. Brasília, DF: Senado Federal, 2016. Disponível em: < https://www2.senado.leg.br/bdsf/bitstream/handle/id/ 518231/CF88_Livro_EC91_2016.pdf>. Acesso em: 24 jan. 2017.

CASTELO, R. O social-liberalismo. Auge e crise da supremacia burguesa na era neoliberal. São Paulo: Expressão Popular, 2013.

CHOSSUDOVSKY, M. La globalizzazione della povertà. L'impatto delle riforme del Fondo monetario internazionale e della Banca mondiale. Torino: Gruppo Abele, 1998.

COUTINHO, C. N. Democracia: um conceito em disputa. Fundação Lauro Campos, São Paulo, 22 dez. 2008. Disponível em: <http:/ /www.educacao.mppr.mp.br/arquivos/File/gestao_democratica/kit2/democracia_um_conceito_em_disputa.pdf $>$.Acesso em: 04 jul. 2016. ENTENDA o que está em jogo com a PEC 241. Carta Capital, 07 out. 2016. Disponível em: <http://www.cartacapital.com.br/politica/ entenda-o-que-esta-em-jogo-com-a-pec-241>. Acesso em: 02 dez. 2016.

FERNANDES, F. A revolução burguesa no Brasil. Ensaio de interpretação sociológica. 5. ed. São Paulo: Globo, 2006.

FRIEDMAN, M. Capitalismo e liberdade. Rio de Janeiro: LTC, 2016.

HARVEY, D. O neoliberalismo: história e implicações. 4. ed. São Paulo: Loyola, 2013.

HAYEK, F. von A. Legge, legislazione e libertà: Critica dell'economia pianificata. Milano: Il Saggiatore, 1986.

. La società libera. Firenze: Edizione Seam, 1996.

KATZ, C. Neoliberalismo, neodesenvolvimentismo, socialismo. São Paulo: Expressão Popular, 2016.

LUKÁCS, G. As bases ontológicas do pensamento e da atividade do homem. Temas de Ciências Humanas, São Paulo, n. 4, p. 1-18, 1978.

MACÁRIO, E. Neodesenvolvimentismo e questão social: reflexões baseadas em dados do Brasil e Ceará. In: CUNHA, A. M.; SILVEIRA, I. M. M. da (Org.). Expressões da questão social no Ceará. Fortaleza: UECE, 2014. p. 61-92.

MARX, K. Crítica ao Programa de Gotha. Observações sobre o Programa do Partido Alemão. In: ANTUNES, R. (Org.). A dialética do trabalho. Escritos de Marx e Engels. São Paulo: Expressão Popular, 2005. p. 101-124.

. A revolução antes da revolução. São Paulo: Expressão Popular, 2008.

MOTA, A. E. (Org). As ideologias da contrarreforma e o Serviço Social. Recife: UFPE, 2010.

MUSTAFÁ, M. A. A Luta E O Pensamento Das Mulheres: O Viés Revolucionário. In: AMARO, S.; DURAND, V. Veias feministas: memória, desafios e perspectivas para as mulheres do século XXI. Rio de Janeiro: Bonecker, 2017. p. 33-52.

OXFAM. Uma economia para os 99\%. Documento Informativo da OXFAM. Oxfam Internacional, Oxford, jan. 2017. Disponível em: $<$ https://www.oxfam.org.br/sites/default/files/economia_para_99-relatorio_completo.pdf $>$. Acesso em: 18 abr. 2017.

RITZER, G. Teoria sociologica. Milano: Apogeo, 2012.

SALVADOR, E. et al. (Org.). Financeirização, fundo público e política social. São Paulo: Cortez, 2012.

SANTOS, J. S. Neoconservadorismo pós-moderno e Serviço Social brasileiro. São Paulo: Cortez, 2007.

TOGNONATO, C. Economia senza società. Oltre i limiti del mercato globale. Napoli: Liguori, 2014.

WAPSHOTT, N. Keynes e Hayek: as origens - e a herança - do maior duelo econômico da história. Rio de Janeiro: Record, 2016.

\section{Notas}

1 Uma das suas primeiras proclamações foi a abolição do sistema da escravidão do salário de uma vez por todas. Em semanas, a recém nomeada Comuna de Paris introduziu mais reformas do que todos os governos nos dois séculos anteriores combinados. Sobre esse importante momento histórico sugerimos a leitura do livro A revolução antes da revolução, volume II, que reune as obras de Karl Marx - As lutas de classes na França, O 18 Brumário de Luis Bonaparte e A Guerra Civil na França.

2 Particularmente sobre a experiência da Comuna de Paris temos como o exemplo da elaboração de sua Constituição que instituiu o direito ao trabalho e todos os direitos referentes à condição de trabalhador e trabalhadora, se procedeu à nacionalização da propriedade eà participação dos conselhos de fábrica e das associações na administração pública eà publicização dos serviços de saúdee deeducação. Notocanteà igualdade entre os sexos, a URSS teve avanços surpreendentes, especialmente no mundo do trabalho: a participação das mulheres e implementação de medidas no sentido da melhoria das condições de trabalho remunerado e da estatização de serviços que substituíssem o trabalho doméstico não remunerado - criação de creches, restaurantes e lavanderias comunitárias, a igualdade de gêneros na tomada de decisões sobre a administração pública e na ação política. A corrente marxista tem impactos positivos nas sociedades ocidentais até os dias atuais e inspira, teórica e praticamente, os rumos que assumirame assumem os movimentos de mulheres e os movimentos feministas. Suas conquistas reais, após a Revolução de Outubro, se fizeram sentir pelo reconhecimento formal e concreto de iguais direitos entre homens e mulheres no campo da política, do trabalho e no âmbito das relações conjugais - legalização do 
divórcioe do aborto - na sociedade soviética. Todavia, a história registra, também, o retrocesso de tais conquistas, na sociedade socialista, especialmente após a experiência stalinista, que recupera as formas mais tradicionais do predomínio masculino. (MUSTAFÁ, 2017).

3 Com efeito, o posicionamento neoliberal, em sua forma primitiva, não passava de uma oposição estratégica de enfrentamento das crises do capital, polêmica antiga assumida pelos economistas Keynes e Hayek. Por um lado, Keynes, que havia escrito The Economic Consequences of the Peace, como alerta de que as precondições para o extremismo, no tocante a retaliações com a Alemanha e países perdedores da primeira guerra mundial, não deveriam ter permissão para se desenvolver. Suas lições foram incorporadas nos tratados do pós-Segunda Guerra e, ao invés de punir os derrotados com a pobreza, os contribuintes americanos os ajudaram a se tornar prósperos por meio do Plano Marshall. Assim, "a Europa dilacerada pela guerra tornou-se um laboratório do keynesianismo [...]", que previa o uso da renda nacional e as estimativas de gastos do orçamento para a formulação de políticas, tendo como meta nacional o pleno emprego, assegurado pelo volume de investimento e gastos federais que fossem necessários: "a derradeira responsabilidade... criar demanda para todo trabalhador à procura de emprego, deve ser tomada pelo Estado". "Com os russos na soleira da porta da Europa Ocidental", o Estado de bem-estar social tornou-se medida chave nos países do continente europeu (WAPSHOTT, 2016, p. 272-274). Ao contrário do que propunha Hayek, a intervenção do Estado na economia estava legitimada pelos governos liberais e permitiu, até seu esgotamento, os chamados trinta anos gloriosos do capital.

4 A definição de liberdade com a qual compartilhamos vai na direção oposta àquela dos liberais. Trata-se de um conceito que entende o sujeito enquanto um ser histórico e ético, que a partir de sua capacidade teleológica consegue, através das práxis, transformar a si mesmo e o mundo ao seu redor. Nesse sentido, concordamos com o marxista húngaro Georg Lukács ao afirmar a liberdade como a possibilidade de realizar escolhas, entre as alternativas possíveis contidas no real, a fim de atender às necessidades postas ao devir-humano dos seres humanos. É então uma categoria central para a compreensão da práxis ética. Assim, “O homem deve adquirir sua própria liberdade através de sua própria atuação. Mas ele só pode fazê-lo porque toda sua atividade já contém, enquanto parte constitutiva necessária, também um momento de liberdade“. (LUKÁCS, 1978, p. 18).

5 Utilizamos, aqui a expressão questão social, no sentido apresentado por Netto (2001), segundo o qual, esta começou a ser utilizada na terceira década do séc. XIX para designar as manifestações políticas da classe trabalhadora frente as constantes formas de exploração do capitalismo monopolista. Inicialmente presente nos discursos de pensadores conservadores, tal expressão posteriormente passa a fazer parte do vocabulário crítico e marxista. Para o autor, a questão social é atrelada ao modo de produção capitalista, pois é somente nesse modo de produção que ocorre a proliferação do pauperismo em um pólo e a enorme concentração de riquezas, no outro pólo, através do processo de produção. Assim, a questão social expressa as manifestações concretas do processo de acumulação do capital, que por meio de sua (re)produção orgânica e subsunção do trabalho pelo capital, produz a desigualdade social, o crescimento da pauperização absoluta e relativa e a luta de classes. Iamamoto (2009) afirma que foram as lutas sociais históricas dessa classe que contribuíram com o processo de reconhecimento da questão social enquanto objeto de intervenção do Estado e legalização de direitos e politicas sociais. Logo, define a autora, questão social é também expressão de rebeldia.

6 Vale ressaltar a criação em 2011 do BRICS (Brasil, Russia, India, China e Africa do Sul), um grupo de cooperação econômica que visa reunir os países considerados de mercado emergente.

7 Para um estudo mais aprofundado do período caracterizado como neodesenvolvimentista sugere-se a leitura de Macário (2014) e Mota (2010).

8 Como se sabe, o termo macarthismo deriva do nome do senador republicano de Wisconsin Joseph McCarthy. O termo traz consigo uma conotação de acusação falsa, até mesmo histérica, e de ataque governativo às minorias políticas.

\section{Maria Alexandra da Silva Monteiro Mustafá}

ethisophias@gmail.com

Doutorado em Filosofia pela Università Pontificia Salesiana di Roma (UPS)

Professora Associada II do Departamento de Serviço Social e do do Programa de Pós-Graduação em Serviço Social da Universidade Federal de Pernambuco (UFPE)

Coordenadora do Movimento pelo Intercâmbio entre o Serviço Social brasileiro e italiano (UFPE/Università Roma Tre/Università di Milano Bicocca/IASSW)

\section{UFPE}

Av. Prof. Moraes Rego, 1235 - Cidade Universitária

Recife - Pernambuco - Brasil

CEP: $50.670-901$

\section{Salyanna de Souza Silva}

salyannass@gmail.com

Doutorado em Serviço Social pela Università degli Studi Roma Tre (UNIROMA3)

Bolsista CAPES/Programa Nacional de Pós-Doutorado junto ao Mestrado Acadêmico em Serviço Social, Trabalho e Questão Social da Universidade Estadual do Ceará (UECE)

Membro do Movimento pelo Intercâmbio entre o Serviço Social brasileiro e italiano (UFPE/Università Roma Tre/Università di Milano Bicocca/IASSW) 


\section{UECE}

Mestrado Acadêmico em Serviço Social, Trabalho e Questão Social

Av. Dr. Silas Munguba, 1700 - Campus do Itaperi

Fortaleza - Ceará - Brasil

CEP: 60.741-000

\section{Gisele Caroline Ribeiro Anselmo}

gribeiroanselmo@gmail.com

Doutorado em Serviço Social pela Università degli Studi Roma Tre (UNIROMA3)

Membro do Movimento pelo Intercâmbio entre o Serviço Social brasileiro e italiano (UFPE/Università Roma Tre/Università di Milano Bicocca/IASSW)

\section{Agradecimentos}

Agradecemos à Universidade Federal de Pernambuco (UFPE), ao Grupo de Estudos e Pesquisas sobre Ética - GEPE e do Movimento pelo Intercâmbio entre o Serviço Social brasileiro e italiano pela possibilidade de interlocução entre as pesquisadoras. Agradecemos, ainda, ao Mestrado Acadêmico de Serviço Social, Trabalho e Questão Social (MASS) da Universidade Estadual do Ceará (UECE) por acolher como bolsista de PNPD uma das autoras deste artigo. Agradecemos a Coordenação de Aperfeiçoamento de Pessoal de Nível Superior (CAPES) que entre os períodos de 2012 a 2016 (BEX: 0549/2012-6) forneceu uma bolsa de Doutorado Pleno no Exterior para uma das autoras e, entre os períodos de 2014 a 2016 (BEX: 13742/13-2) para uma das autoras.

\section{Agência financiadora}

Coordenação de Aperfeiçoamento de Pessoal de Nível Superior (CAPES):
Número: BEX: 0549/2012-6. Período de vigência: 2012-2016.

Número: BEX: 13742/13-2. Período de vigência: 2014-2016.

\section{Contribuições dos autores}

As autoras participaram igualmente de todas as etapas da elaboração do trabalho.

Aprovação por Comitê de Ética e consentimento para participação

Não se aplica.

\section{Consentimento para publicação}

Não se aplica.

Conflito de interesses

Não existem conflitos de interesses. 